\title{
MACHINING OF THIN BLADE USING VIBRATION PREDICTION AND CONTINUOUS SPINDLE SPEED CONTROL
}

\author{
P. Vavruška ${ }^{1}$, M. Sulitka ${ }^{1}$, M. Stejskal ${ }^{1 *}$, A. Šimůnek ${ }^{1}$, J. Falta ${ }^{1}$, P. Heinrich², M. Kopal ${ }^{2}$ \\ ${ }^{1}$ Czech Technical University in Prague, Research Center of Manufacturing Technology, Prague, Czech Republic \\ ${ }^{2}$ KOVOSVIT MAS Machine Tools, a.s., Czech Republic \\ ${ }^{*}$ Corresponding author; e-mail: m.stejskal@rcmt.cvut.cz
}

\begin{abstract}
The paper focuses on the issue of controlling the cutting conditions in finishing machining of compliant workpieces, such as typically thin blades, in order to eliminate undesirable vibration and achieve high quality machined surfaces while also increasing productivity in machining processes. Workpiece vibration along the toolpath results from excitation of the workpiece by cutting forces. A strategy of calculating the overall level of workpiece vibration excited by cutting forces at different spindle speed levels as a multifrequency problem was proposed for specific use with long thin blades. The proposed strategy allows for very efficient identification of blade sections with critical increase of vibration level at different spindle speed values. This enables determination of the optimized spindle speed levels and feed rate along the blade to avoid increased workpiece vibration. A method for continuous control of the spindle speed and feed rate during finishing machining was proposed and successfully tested and verified through real machining tests. The machined surface quality improvement was proven.
\end{abstract}

Keywords:

Machining; Optimization; Spindle speed control; Feed-rate control; FEM analysis; Deformation; Quality

\section{INTRODUCTION}

In most cases, milling of complex shape parts consists of very long or many shorter finishing toolpaths. The machining time of finishing milling strategies is generally long due to high demands on surface quality and roughness. Another issue arises in machining of thin wall workpieces with elevated compliancy, due to which the cutting conditions are usually selected in a conservative manner according to the most critical section of the workpiece. When the technologist defines the toolpath tolerance value, toolpath strategy and a number of toolpaths (or scallops), optimization of cutting conditions may follow to eliminate the workpiece elevated vibration and increase machining productivity.

The issue of optimizing the cutting conditions for machining of compliant workpieces has been addressed by many authors. Most papers addressing this topic are focused on cutting condition optimization based on computation of cutting forces. [Sarasua 2014] implemented calculation of cutting forces to allow users to visualize the cutting force map during toolpath preparation in the CAM system. Another optimization of cutting conditions is presented by [Tunc 2009], where the authors developed a method to calculate the actual contact area between the tool and the workpiece in order to predict the cutting forces. [Baek 2007] and [Erkorkmaz 2013] used complex cutting process models that include several control system parameters. This improves the accuracy of cutting condition optimization.
The reduction of machining time by pre-process control of spindle speed and feed rate was resolved by [Vavruska 2018]. The main goal is to achieve the required cutting speed at an almost constant level during point milling strategies, when the real cutting diameter continuously varies, through continuous control of the spindle speed. To maintain the feed per tooth at a constant value, the feed rate is also controlled, which saves time.

Setting suitable cutting conditions in a machining process plays a key role in achieving the required machining efficiency and productivity. Testing these conditions in trials has turned out to be a very costly method of finding the optimal machine and process settings. Mathematical simulation methods have been developed in order to make machining process reproducibility much simpler and less expensive. The models have been designed so that they capture the real phenomena causing errors in the machining process. As a result they are often used to test experimental methods proposed to reduce the occurrence of errors.

Essentially there are two sources of vibration - forced and self-excitation. It is possible to suppress the former, either by reducing an alternating component of force or changing the fundamental frequency to avoid resonance. The latter source of vibration is fundamentally different and relevant suppression methods require a more complex approach.

[Fei 2018] built a model to show that support of a thin wall structure with a moving element on the back surface of the structure leads to effective deformation suppression. [Wang 2017] proposed a cutting process model and 
an optimization scheme that finds the ideal material volume removal strategy while keeping workpiece deformation at an acceptable level. [Huang 2017] proposed a method to minimize the impeller blade deformation by adjusting the tool orientation. [Sun 2018] presented a model that enables chatter stability prediction. [Budak 2012] presented a method for avoiding self-excited vibration on thin wall workpieces and improving machining time by splitting the machined surface into several parts with different depths of cut and spindle speeds. The model includes varying workpiece dynamics due to material removal. [Zhang 2013] attempted to find the cutting conditions that would minimize tool vibration and maximize the material removal rate, while keeping the milling process in a stable regime.

[Bolsunovskiy 2013] solved the problem of how to avoid resonance during blade machining that is caused by a change of natural frequency linked to stock removal. The method was based on avoiding the intersection of natura frequency curves and the discrete spectrum of a cutting force at each Z-level.

If the cutting conditions provide a stable cut, a common approach to eliminate undesirable thin wall workpiece vibration uses the strategy of avoiding workpiece resonance frequency excitation by cutting forces. This paper proposes an innovative strategy consisting of evaluation of the overall level of forced vibration of a flexible workpiece. This information is used as a parameter for finding the optimized spindle speed and feed rate using the criterion of vibration level minimization, which consequently improves the machined surface quality and removes the vibration marks on the surface, while also reducing the machining time. The strategy is applied on a long thin wall steam turbine blade. At each height of the blade, sensitivity maps of average workpiece vibration response to cutting force excitation at different spindle speed levels are calculated. This finding is used to optimize the spindle speed and feed rate along the blade by keeping the given tool path.

The paper is organized as follows: Chapter 3331 introduces the continuous spindle speed method, Chapter 3332 describes the case study and Chapter 4 explains the fundamentals of the mathematical model. Chapter 5 includes verification of the proposed strategy and discussion of the results.

\section{APPROACH TO PRODUCTIVE MACHINING OF A LONG THIN WALL BLADE}

Productive machining of complex shapes, such as long thin blades, is a technologically demanding task requiring the highest quality while minimizing machining time. These workpieces, which have a low dynamic stiffness, represent a difficult task in terms of balancing the prescribed quality and precision with productivity. Machining such workpieces often leads to locally deteriorated surface quality due to higher vibration levels. In the industrial environment, these issues are usually addressed by experimental fine-tuning of the cutting conditions for the entire NC code. This means reducing the cutting conditions in the NC code according to the problematic section of the toolpath, which in the cases in question represents only a minor percentage of the entire operation. In this way, the area where surface quality is impaired due to a higher level of forced vibrations can indeed be avoided, but overall the method lacks effectiveness. Another option is to define the borderline between the excited and unexcited areas of the workpiece using a model that simulates the response to vibrations excited by the cutting process. For these areas, the NC code is firmly divided so as to assign particular suitable cutting conditions to each NC code. This option is effective, but it introduces the crucial problem of impaired surface quality in the connecting area between two successive NC codes on continuous surfaces, see Fig. 1

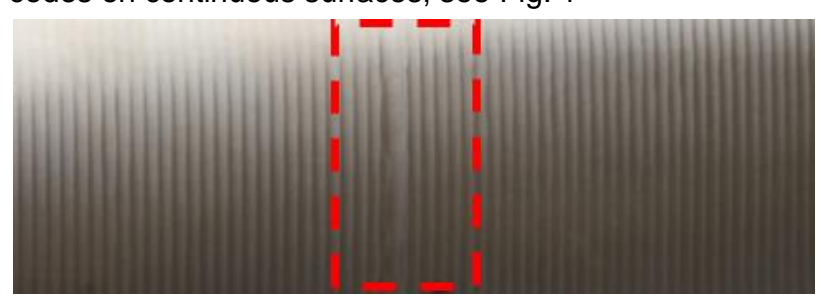

Fig. 1: Defect between two NC codes on a continuous surface.

Therefore, this article will examine a third, innovative method in which the cutting conditions, namely the spindle speed and feed rate within one NC code, are controlled continuously according to recommendations from the mathematical model. Thus surface quality impairment can be efficiently prevented while productivity is increased. Continuous control of the spindle speed and feed rate has been already described in the paper [Vavruska 2018]. The principle of the innovative method is illustrated on a sample single blade, see Fig. 2.

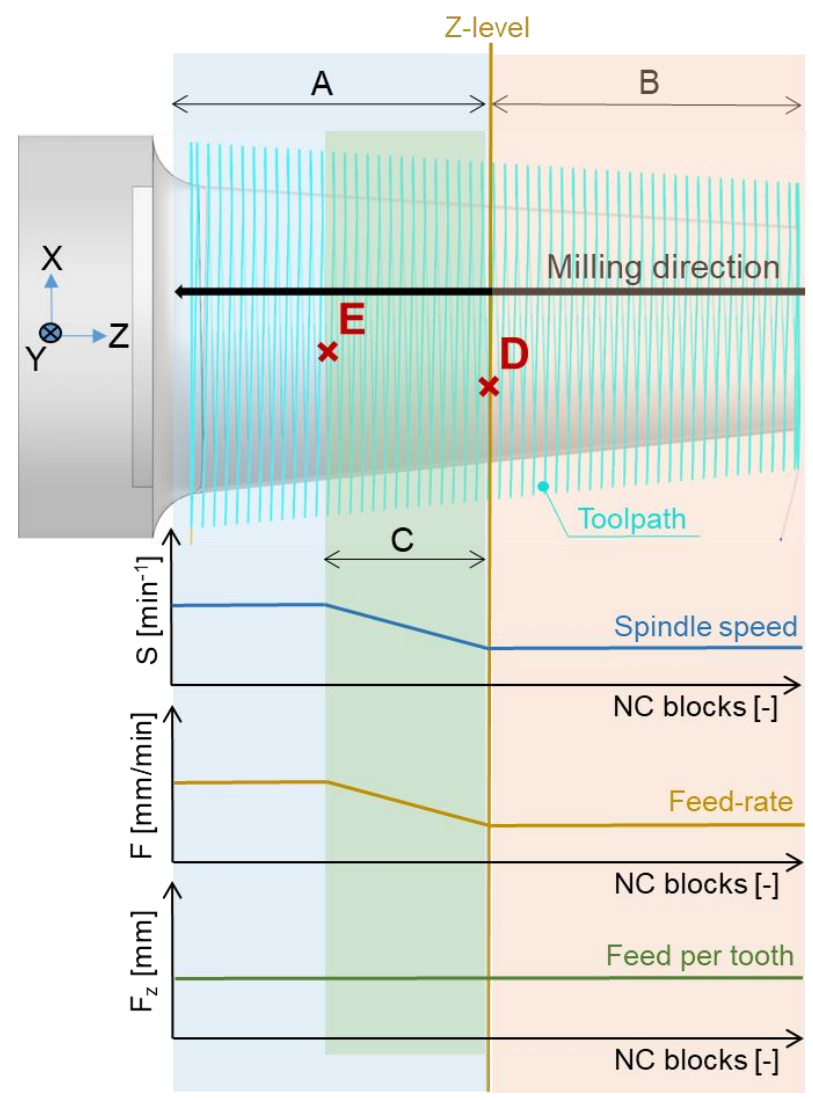

Fig. 2: Method of continuous control of cutting conditions.

The single blade is finished by a helical-strategy from the compliant end towards the stiffest segment. This is a typical machining procedure for parts of this type. The optimization method is based on three data items from the model simulating the response to vibrations excited by the cutting process. The first is the $Z$ distance from the workpiece coordinate system. Along the $Z$ distance, the toolpath is to be divided into two areas. The dividing line is determined by the Z-level value. The second input information consists of the suitable cutting conditions for the two areas, i.e. A and 
B. The third input information is area $\mathrm{C}$. Along area $\mathrm{C}$, the cutting conditions continuously change from the original values to the newly calculated values. Points $D$ and $E$ indicate the cross points between the Z-level and the toolpath. Area $C$ is located between points $D$ and $E$. The controlled cutting parameters include the spindle speed $S$ $\left[\mathrm{min}^{-1}\right]$ and the feed rate $\mathrm{F}[\mathrm{mm} / \mathrm{min}]$. These parameters change for each NC block within area $\mathrm{C}$. The input value for calculating the cutting conditions is the spindle speed. It is used to calculate the feed rate, strictly observing the feed per tooth Fz [mm]. The feed per tooth greatly impacts the resultant surface quality.

The described optimization method is implemented through an optimization function integrated in the postprocessor. There are three input data items needed for the optimization function. The first is the required cutting condition values for the given area. The second is the value of the Z-level where the area starts. The third is the definition of the area where the continuous change of the cutting conditions from the original values to the new values will begin. Fig. 3 shows a schema of the optimization method with the integrated optimization function in the postprocessor. Symbol A indicates the initial data input path through the CAM interface. Symbol B indicates the data input path directly in the postprocessor.

- Dividing level and

- Cutting conditions

- Area for changing of cutting conditions

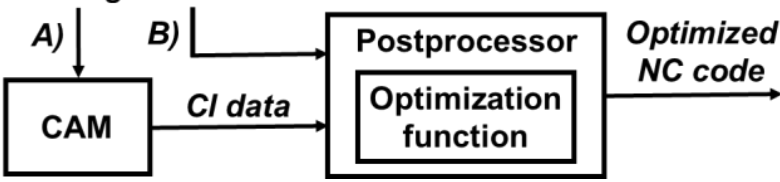

Fig. 3: Scheme of optimization function into the postprocessor.

In order to achieve stepless spindle speed and feed rate control, the proper functionality of the optimization method requires the spindle speed profile to be known. Spindle angular acceleration is not commonly known, since today stepless spindle speed change is not envisaged for CNC machining. The spindle angular acceleration can be measured using diagnostic functions in machine control systems, such as SERVOTRACE for SIEMENS. Another option is to measure the speed over time externally, for instance using a laser speed sensor. Fig. 4 shows a schematic chart of the optimization method suitability.

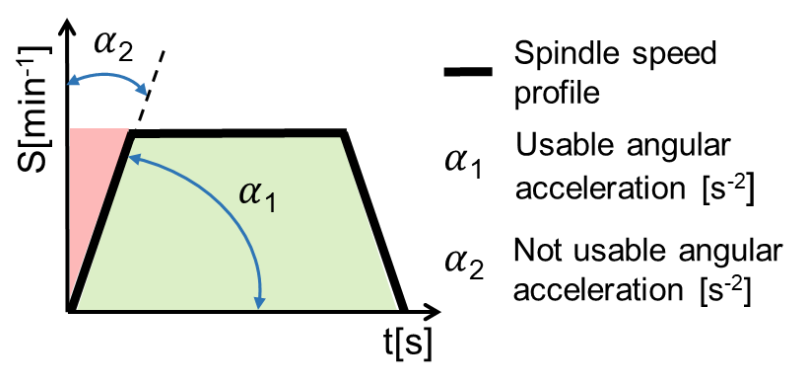

Fig. 4: Achievable spindle speed profiles.

The green area enclosed by the solid black line determines the spindle speed profile. An important parameter is the angular acceleration labelled $\alpha 1$. In this $\alpha 1$ area, the spindle speed can be steplessly controlled as needed and thus an optimization method can be used. Where the angular acceleration requirement is in the $\alpha 2$ area (shown in red), the optimization method cannot be used. This is very unlikely to occur when machining the type of workpieces in question.

\section{CASE STUDY}

The case study focused on finishing a steam turbine blade made of difficult-to-cut stainless steel DIN 1.4462. The initial semi product was a workpiece made by die drop forging.

Manufacture of such parts is typical for multifunctional milling machining centres where the blade segment is clamped between the main and sub spindles. The main and sub spindles most frequently operate in the master-slave mode. Extremely thin and therefore compliant parts need to be supported by a steady in order to avoid unstable cutting, which might cause damage to the part and to the tool/machine. The steady is attached to a bottom support in these types of machines. The final steam turbine blade is $1,100 \mathrm{~mm}$ long (meaning the single-clamp machining distance between two clamps on the main and sub spindles) and its maximum gauge in the minimum cross-cut is $2.5 \mathrm{~mm}$, Fig. 5. The angle between the blade locks is $90^{\circ}$.

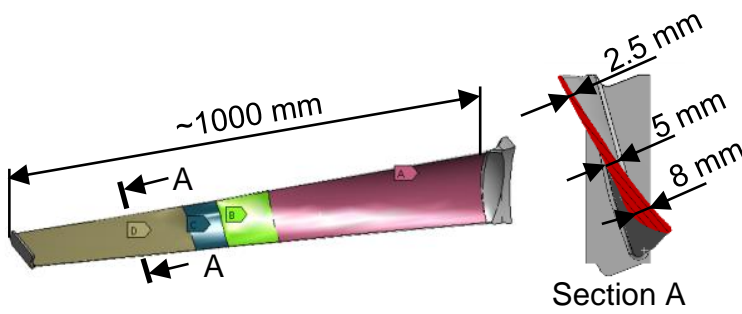

Fig. 5: Case study: a compliant steam turbine blade.

The machine selected for manufacturing the steam turbine blade was a Kovosvit MAS Multicut 630 mill-turn machining centre, see

Fig. 6. The maximum machining length is $3,100 \mathrm{~mm}$, the largest machining diameter at spindle head tilt $\left(B=90^{\circ}\right)$ is $1,150 \mathrm{~mm}$, travel in $\mathrm{Y}$ is up to $400 \mathrm{~mm}$, and the spindle head tilt $(B)$ is $+-120^{\circ}$. The maximum spindle speed of the machine is $1,200 \mathrm{~min}^{-1}$. The spindle clamp interface is CAPTO C8. The machine control system is Sinumerik 840D SL, version 4.7 by SIEMENS.

A toroidal cutter with an unequal blade pitch, $15 \mathrm{~mm}$ diameter and $1 \mathrm{~mm}$ edge radius was selected for the finishing of the functional surface of the turbine blade, see Fig. 7.

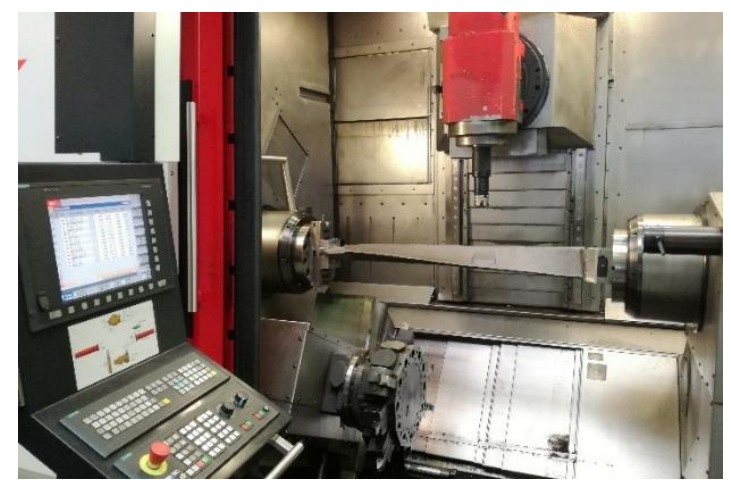

Fig. 6: Kovosvit MAS MTC 630 mill-turn machining centre. 


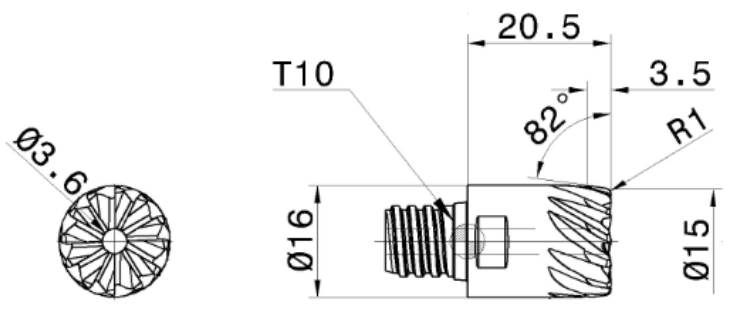

Fig. 7: Toroidal cutter (MM ET15/8H4R10CF-12T10H) by ISCAR.

With respect to the extensive functional surface area of the blade, the optimal lead angle had to be selected (vertical to the surface at the contact point between the workpiece and the tool). The monitored parameters were the number of paths required to achieve the requested scallop (height of the difference between individual passes of the tool), while the risk of undercutting the blade surface with an unsuitable part of the tool, e.g. an insufficiently leaded tool, also had to be minimized. And it was also critical to avoid an over-lead angle for the tool, not only because it increases the number of required paths, but also because of how it affects the need for more extensive restructuring of the tool kinematics, i.e. greater demands on acceleration of tool motion axes.

Applying these facts and studies of tool load at various lead angles, a suitable lead angle of $12^{\circ}$ was selected. The impact of the lead angle selection on productivity with respect to achieving the required surface scallop and force load is not the subject of this paper. The lead angle was also considered during preparation of the technology. However, considering this parameter led to a significant increase in the number of toolpaths required, and thus to lower finishing efficiency.

The selection of cutting conditions was primarily influenced by the machinability of the material. Nonetheless the final cutting speed $\left(v_{c}\right)$ was relatively high, due to the inclusion of the small chip cross-section in the cutting speed calculation. The speed should be in the range of $\mathrm{v}_{\mathrm{c}}=50$ - $70 \mathrm{~m} / \mathrm{min}$, yet it could have been increased to $198 \mathrm{~m} / \mathrm{min}$ in regard to the aim of increasing finishing efficiency, without any negative impact on the surface quality or service life of the tool. The selected feed per tooth $\left(F_{z}\right)$ value was $0.02 \mathrm{~mm}$. The machining strategy was helical with a constant lead angle. The CAM settings for the finishing operation are shown in Tab. 1.

\begin{tabular}{|c|c|}
\hline \multicolumn{2}{|c|}{ CAM settings } \\
\hline Scallop & $0.01 \mathrm{~mm}$ \\
\hline AdOC & $0.3 \mathrm{~mm}$ \\
\hline Lead angle & $12^{\circ}$ \\
\hline Tilt angle & $0^{\circ}$ \\
\hline CAM tolerance & $0.003 \mathrm{~mm}$ \\
\hline Tool diameter & $15 \mathrm{~mm}$ \\
\hline Tool radius & $1 \mathrm{~mm}$ \\
\hline
\end{tabular}

During the first standard procedure the cutting conditions were set according to the tool and machine limits to achieve maximum productivity. The entire blade was machined under these cutting conditions. The result showed unacceptable local deterioration of the surface quality due to the forced vibrations, see Fig. 8. The limit parameters were $\mathrm{S}=4,200 \mathrm{~min}^{-1}$ and $\mathrm{F}=1,250 \mathrm{~mm} / \mathrm{min}$.

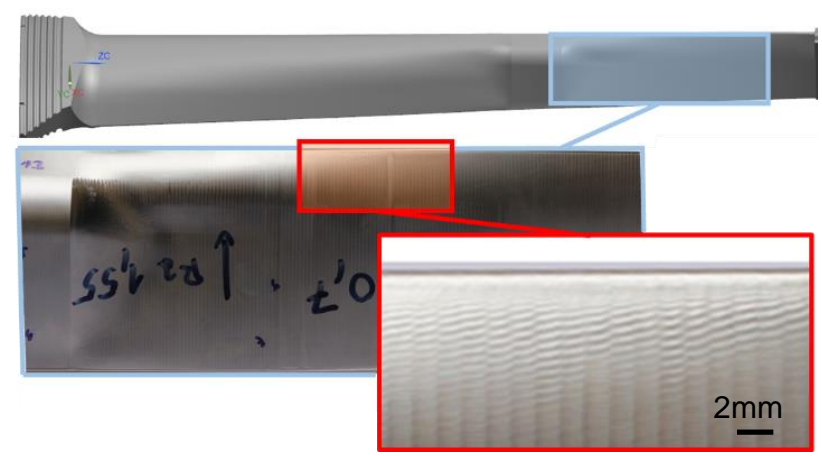

Fig. 8: Deteriorated surface quality due to vibration.

In the next step, suitable cutting conditions had to be found which would minimize the forced vibrations and thus improve the surface quality. The mathematical model was developed for this purpose.

\section{PROPOSED APPROACH}

The goal of the proposed approach is to determine the optimized spindle speed in CNC machining of long slender blades. The approach takes into account productivity, accuracy and quality of the machined surface. The model is limited to finishing operations where the surface quality requirement is critical and it is also reasonable to assume that workpiece compliance calculated by FEA is not significantly affected by material removal. The strategy considers the phenomena of forced vibration.

\subsection{Simulation of cutting forces}

Total cutting force is calculated as an integral of the specific cutting force along the engaged cutting edge $\Gamma$

$$
\boldsymbol{F}=\int_{\Gamma} g(s, \varphi)[T]\left(\boldsymbol{K}_{\boldsymbol{e}}+\boldsymbol{K}_{\boldsymbol{c}} h\right) d w
$$

where $\mathrm{g}$ is a characteristic function of the engagement, $[T]$ is a transformation matrix from the local coordinate system of the cutting edge element to the global coordinate system, $\boldsymbol{K}_{\boldsymbol{e}}=(40,40,0)^{\top} \mathrm{Nm}^{-1}$ and $\boldsymbol{K}_{\boldsymbol{c}}=(2600,1300,0) \mathrm{Nm}^{-2}$ are vectors of cutting force coefficients, $h$ is the undeformed chip thickness and $\mathrm{d} w$ is the chip width, which is calculated by material removal simulation (see Fig. 9). This formulation, though numerically more demanding, simplifies the geometrical complexity of the cutting conditions.

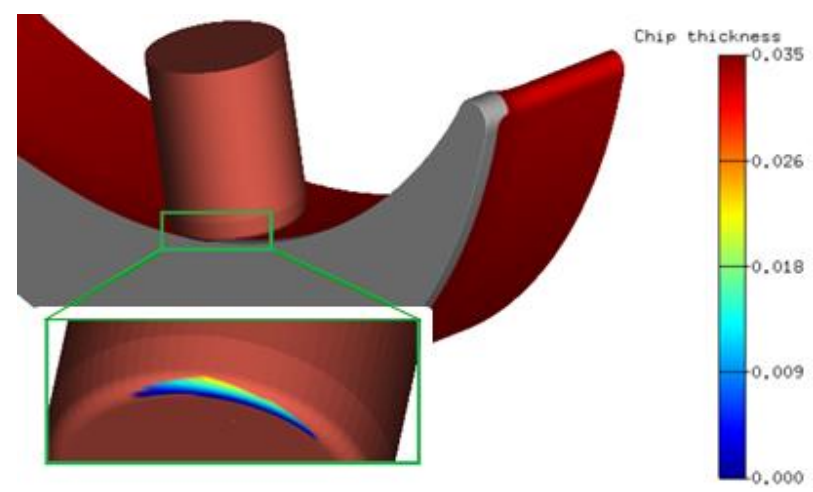

Fig. 9: Example of chip removal simulation.

Cutting force is almost periodic, which means that its spectrum can be modelled as a discrete one. The cutting force depends explicitly on the revolution angle, but not 
explicitly on the spindle speed. This means once the cutting speed is evaluated, it may be scaled by the spindle speed in a time domain. An example of the cutting force calculated for our test case is shown in Fig. 10. A toroidal tool with variable pitch and an inclination angle of $12^{\circ}$ was used.

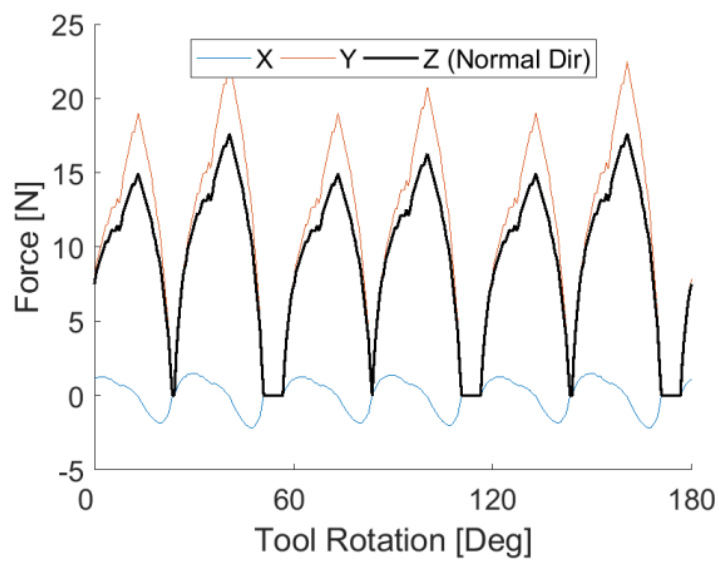

Fig. 10: Cutting forces during tool rotation.

\subsection{Computational model of the blade and its validation}

The dynamic properties of the blade were calculated by FEA software ANSYS. The FE model of the blade was attached at each end to additional supports (blocks of material), representing the blade clamping and dynamics of the machine tool structure. Modal damping and stiffness of the supports was tuned according to the response of the real blade. The FE model consists of 774,000 quadratic tetrahedron elements. A comparison between the mode and measured FRF at one of the points on the blade surface is shown in Fig. 11.

Modal reduction was applied to speed up the calculation of the system response. Eigenfrequencies and eigenvectors were exported from ANSYS and used to calcuate the FRF in the normal direction at each grid point on the workpiece surface.

Due to the high slenderness ratio and the length of the blade, modal shapes in a wide frequency spectrum $(100-1800 \mathrm{~Hz})$ were needed for a relevant description of the blade dynamic behaviour. Modal shapes with compliancy peaks in the critical point on the blade surface and a comparison with the experimental data are presented in Fig. 11.

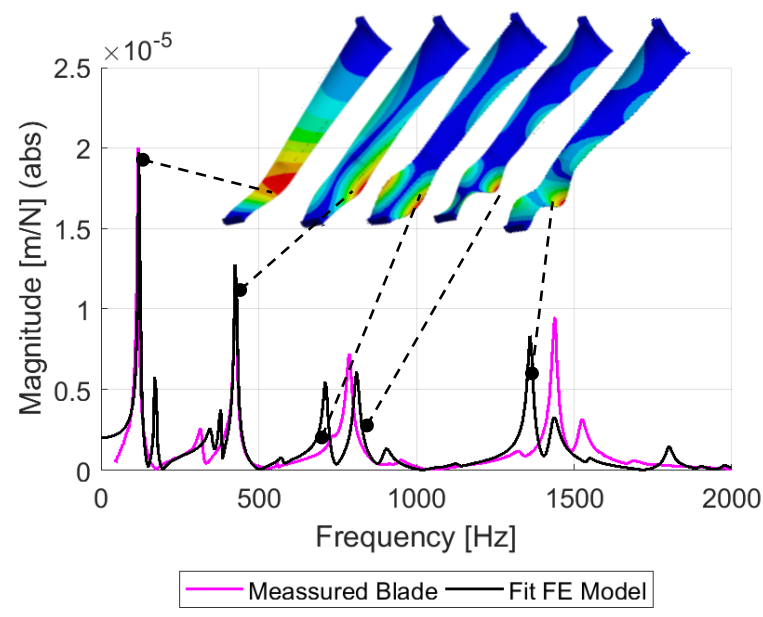

Fig. 11: Comparison of measured and calculated FRF by FE model in the critical point of the blade.
The verification measurements were conducted using an impulse hammer and single-axial accelerometer. The modal hammer was selected to excite the measured blade in the required frequency range up to $2000 \mathrm{~Hz}$ and the accelerometer was selected to avoid affecting the measured blade through its own mass (mass loading effect). The frequency response function (FRF) was calculated using the measured magnitude of the force signal and acceleration. The measurement was conducted at one point $(A)$, see Fig. 12.

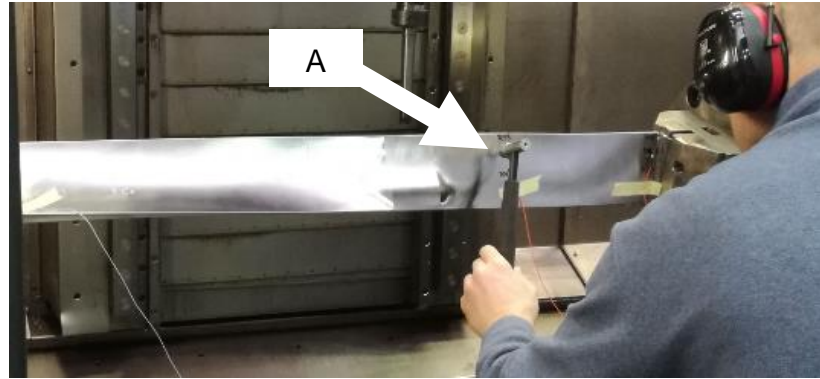

Fig. 12: Impulse testing of the blade by modal hammer.

\subsection{Optimal spindle speed selection strategy}

Our goal was to determine the spindle speed as a function of Z-level $\Omega(z)$ which minimizes the mean value of the total energy of the forced workpiece vibration. The technological constraints regarding the cutting speed, spindle dynamics and machining time were also taken into account. A more detailed description of the calculation is provided below.

The forced vibration is caused by the periodic cutting force (dominantly in the normal direction to the machined surface), which can be expressed as a truncated Fourier series

$$
F \approx \sum_{k=-\mathrm{n}}^{n} \widehat{F_{k}} e^{i \omega_{k} \mathrm{t}}
$$

where $\omega_{k}$ are frequencies of the cutting force spectrum (harmonics of the spindle speed frequency) and $\widehat{F_{k}}$ are the corresponding amplitudes.

The dynamic response of the workpiece to this excitation depends on the eigenfrequencies of the workpiece and the position of the excitation force relative to the respective modal shapes. The spectra of workpiece compliancy and cutting force before their convolution are shown in Fig. 13.

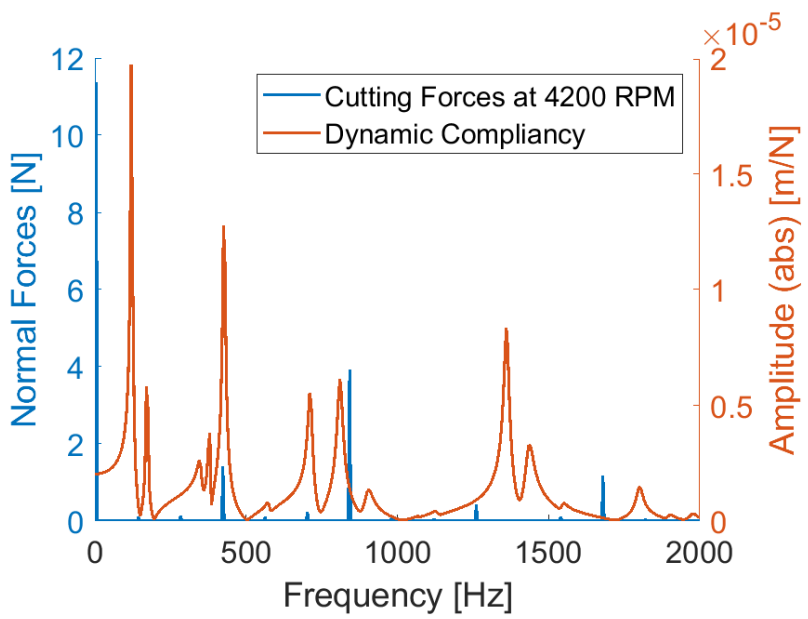

Fig. 13: Spectra of the workpiece and cutting force before their convolution. 
Parseval's theorem was used to calculate the energy norm of the forced vibration at each of the grid points

$$
\left.|| E\right|_{i j}(\Omega)=\sum_{k=1}^{n}\left|\Phi_{i j}\left(\omega_{k}(\Omega)\right) \widehat{F_{k}}\right|^{2}
$$

where $\Phi_{i j}$ is the frequency response function in the normal direction to the surface evaluated at each grid point $x_{i j}$.

The energy norm calculation scheme is shown in Fig. 14.

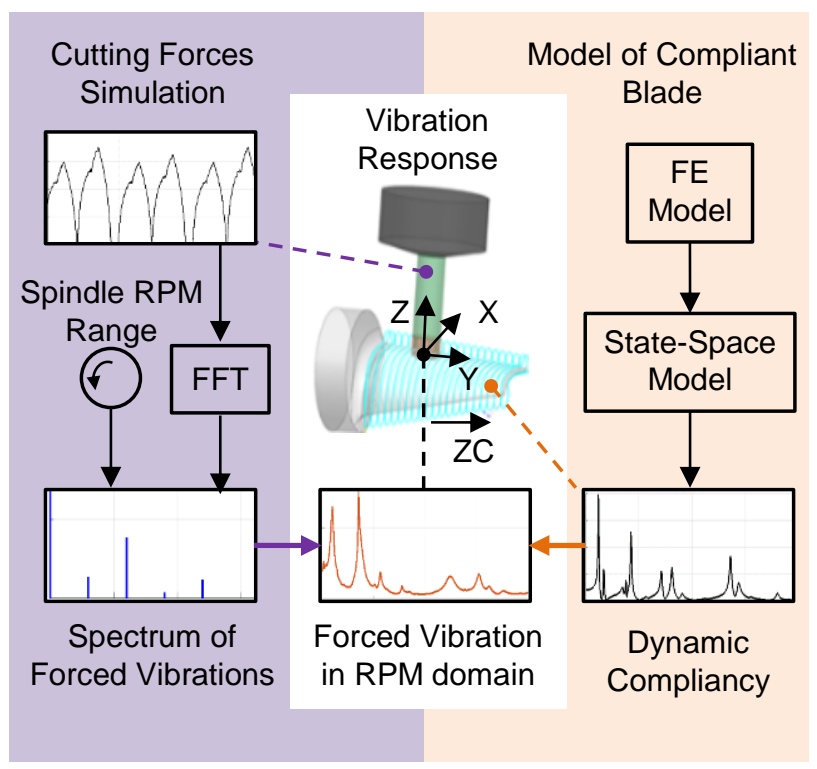

Fig. 14: Method to minimize forced vibrations at a single blade location.

The optimization criterion for spindle speed distribution along the blade is the mean value of the previously calculated total energies along the toolpath. The mean value is approximated as the sum over all grid points

$$
\overline{\|E\|_{C}} \approx \frac{1}{l m} \sum_{i=1}^{l} \sum_{j=1}^{m}\|E\|_{i j}\left(\Omega\left(z_{i}\right)\right)
$$

where $/$ is the number of grid points in the $z$ direction, $m$ is number of grid points at the given $z$ level and $\Omega\left(z_{i}\right)$ is spindle speed at the given $z$ level. Due to the Z-level milling strategy, the spindle speed at each level was considered constant. It is convenient to calculate the mean value of the energy over all grid points at each level

$$
\overline{E_{\imath}}=\frac{1}{m} \sum_{j=1}^{m} E_{i j}
$$

to provide visual control over the optimization process. A surface plot showing the mean energy at each Z-level depending on spindle speed velocity is shown in Fig. 15.

In the current analysis the shape of the spindle speed distribution was restricted to a piecewise linear function with three segments. A possible generalization of the method would be to allow more parameters to define the spindle speed and to consider the toolpath which is not very well aligned with the grid points.

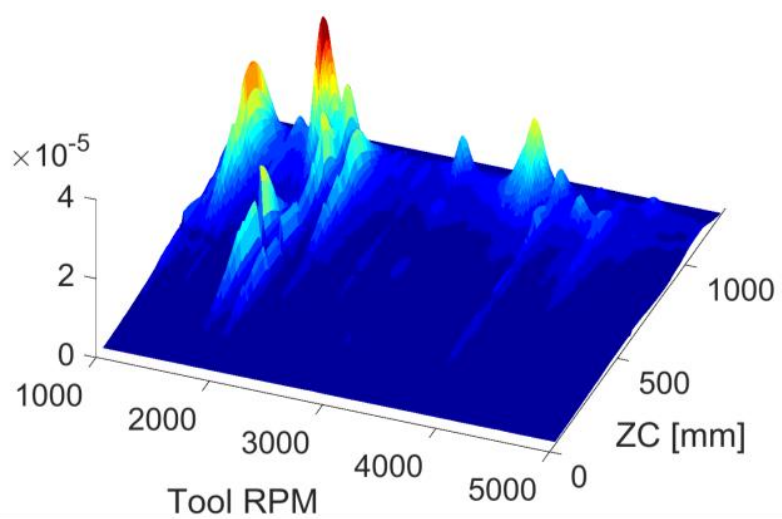

Fig. 15: 3D profiles of the mean vibration energy depending on spindle speed and Z-level.

\section{VERIFICATION OF THE METHOD}

The optimization method based on controlling cutting conditions per a mathematical model was verified by machining a functional prototype of a stainless steel steam turbine. Optimization was planned using a map of critical areas, see Fig. 16. The spindle speed values were selected according to the optimal path with the objective of avoiding potentially critical areas with a risk of deteriorated surface quality due to forced vibrations. From the perspective of productivity, the aim was to control spindle speed at a maximum of 4,200 $\mathrm{min}^{-1}$. Due to strict adherence to the feed per tooth, spindle speed goes hand in hand with productivity, i.e. as spindle speed increases, the feed rate increases. This spindle speed for this machining case is a constraint in relation to exceeding the cutting speed and the possibility of decreasing the durability of the tool (particularly with this workpiece material).

The objective of controlling spindle speed was to avoid the potentially problematic areas shown in red. Conversely, it was advantageous to maintain the spindle speed in the areas with the lowest risk of surface damage due to forced vibrations, i.e. the areas shown in dark blue. The spindle speed progression was selected based on productivity and quality, which is the solid green line marked Soptim.

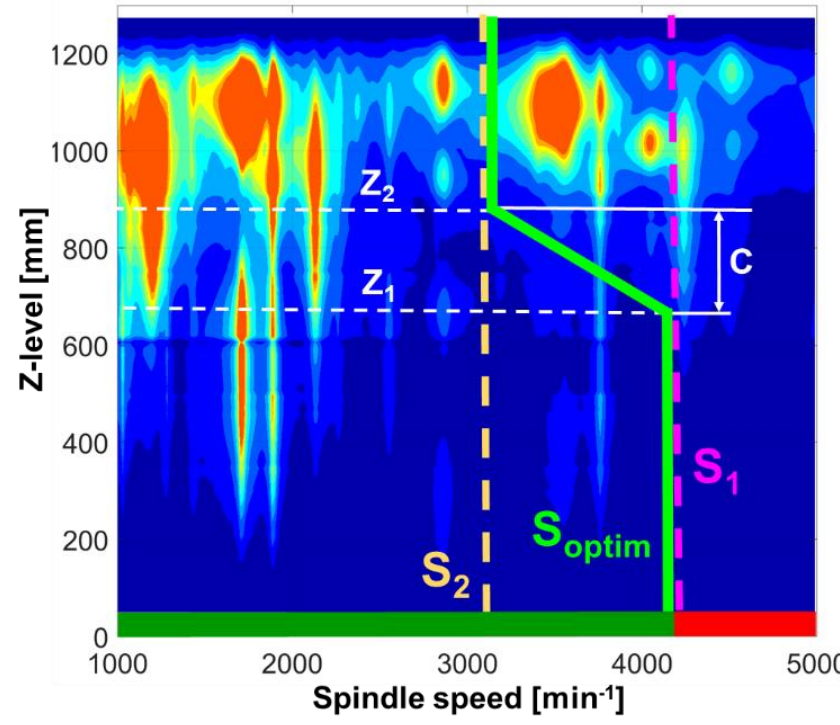

Fig. 16 : Optimized strategy (Soptim) of spindle speed control along the blade Z-level. 
Tab. 2 shows the machining time options. Originally the blade was machined using the cutting conditions at the tool's limit, with a spindle speed of $S=4,100 \mathrm{~min}^{-1}$ and $\mathrm{F}=1,250 \mathrm{~mm} / \mathrm{min}$. This resulted in unsatisfactory surface quality due to excitement of local areas of the blade by the cutting process. Therefore, the aforementioned mathematical blade model was applied to calculate suitable cutting conditions, $S=3,200 \mathrm{~min}^{-1}$ and $F=926 \mathrm{~mm} / \mathrm{min}$. Using these cutting conditions the blade was machined without any deterioration in surface quality in 146 minutes. After application of the developed optimization method with control of spindle speed and feed rate, the time was reduced by 19 minutes while surface quality was maintained, see Fig. 17. The time savings will increase particularly with longer blades and serial production.

Tab. 2: CAM settings.

\begin{tabular}{|c|c|c|c|}
\hline Approach & $\begin{array}{l}\text { Spindle } \\
\text { speed } \\
{\left[\mathrm{min}^{-1}\right]}\end{array}$ & $\begin{array}{l}\text { Machining } \\
\text { time [min] }\end{array}$ & Surface quality \\
\hline $\mathrm{S}_{1}$ & 4200 & 110 & Non-satisfactory \\
\hline $\mathrm{S}_{2}$ & 3200 & 146 & Satisfactory \\
\hline Soptim & Variable & 127 & Satisfactory \\
\hline
\end{tabular}

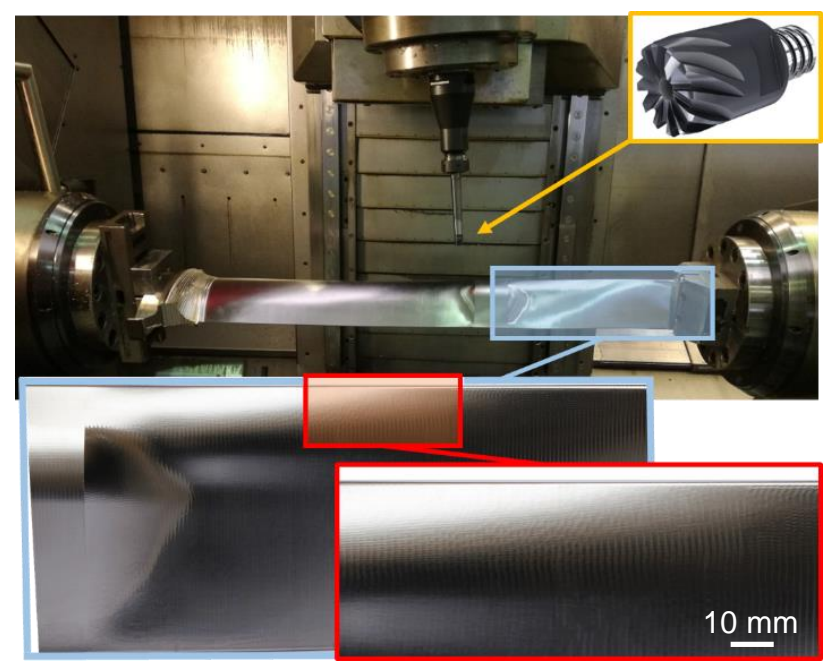

Fig. 17: Final blade after optimized machining.

\section{SUMMARY}

The paper introduces an innovative strategy for the optimization of cutting conditions in machining of thin blades with elevated compliancy using the approach of continuous control of spindle speed and feed rate. The strategy for spindle speed and feed rate optimization is based on an evaluation of the overall energy of workpiece forced vibrations due to periodic cutting forces. In this way, we consider not only the elimination of the blade excitation at resonance frequencies, but also the overall level of blade vibration in the multi-frequency range resulting from the cutting process.

The strategy of finding the optimum cutting conditions is specifically adjusted for finishing machining of long thin blades. For each Z-level of the blade the mean vibration energy is calculated using the FE model of the blade and its excitation by cutting forces. Cutting force simulation employs the mechanistic cutting force model, in which actual material removal during the machining process is considered. A map of vibration energy, parametrized by the spindle speed, is evaluated over the blade surface. This presents an efficient method of finding the optimum spindle speed and feed rate that fulfils the criteria of minimized forced vibration, good surface quality and machining productivity of the blade.

There are two limit points to the approach - firstly, achieving stable machining and secondly, the limits of spindle dynamics.

The proposed strategy was successfully tested and validated using long thin blade finishing machining as a case study. The innovated approach eliminates the need to experimentally test the blade machining at different cutting conditions and to evaluate the surface quality.

Owing to this method, the production efficiency and quality of the resultant workpiece surface were significantly improved. Time savings of about $13 \%$ using the developed optimization strategy were achieved.

The next step will aim to test the developed strategy for different types of workpieces to prove its reliability and the possibility of implementing the method into enhanced procedures of machining technology development.

\section{ACKNOWLEDGMENTS}

The authors would like to acknowledge funding support from the Czech Ministry of Education, Youth and Sports under the project CZ.02.1.01/0.0/0.0/16_026/0008404 "Machine Tools and Precision Engineering" financed by the OP RDE (ERDF). The project is also co-financed by the European Union. Support from the KOVOSVIT MAS Machine Tools company for experiments is also gratefully acknowledged.

\section{REFERENCES}

[Sarasua 2014] Sarasua, J. and Cascon, I. Integration of Machining Mechanistic Models into Cam Software, Journal of Machine Engineering, 2014, Vol.14, No.4, ISSN 18957595

[Budak 2012] Budak E., et al, Prediction of workpiece dynamics and its effects on chatter stability in milling, CIRP Annals, Vol. 61, pp 339-342, ISSN 0007-8506

[Tunc 2009] Tunc, L. T. and Budak, E. Extraction of 5-Axis Milling Conditions from CAM Data for Process Simulation, The International Journal of Advanced Manufacturing Technology, September 2008, Vol.43, pp 538-550. ISSN 1433-3015

[Baek 2007] Baek, K.D. and Tae, J.K, Feedrate scheduling for free-form surface using an NC verification model, International Journal of Machine Tools \& Manufacture, August 2007, Vol. 48, pp 163-172. ISSN 0890-6955

[Erkorkmaz 2013] Erkorkmaz, K., et al. Feedrate Optimization for Freeform Milling Considering Constraints from the Feed Drive System and Process Mechanics, CIRP Annals, 2013, Vol.62, pp 395-398. ISSN 0007-8506 
[Vavruska 2018] Vavruska, P., et al. Reducing Machining Time by Pre-Process Control of Spindle Speed and FeedRate in Milling Strategies, Procedia CIRP, 2018, Vol.77, pp 578-581. ISSN 2212-8271

[Fei 2018] Fei, J., et al. Investigation of Moving Fixture on Deformation Suppression During Milling Process of ThinWalled Structures, April 2018, Journal of Manufacturing Processes, Vol.32, pp 403-411. ISSN 1526-6125

[Wang 2017] Wang, J., et al. A Cutting Sequence Optimization Algorithm to Reduce the Workpiece Deformation in Thin-Wall Machining, Precision Engineering, October 2017, Vol.50, pp 506-514. ISSN 0141-6359

[Huang 2017] Huang, T., et al. Tool Orientation Optimization for Reduction of Vibration and Deformation in Ball-end Milling of Thin-walled Impeller Blades, Procedia CIRP, 2017, Vol.58, pp 210-215. ISSN 2212-8271

[Sun 2018] Sun, Y. and Shanglei, J. Predictive Modeling of Chatter Stability Considering Force-Induced Deformation
Effect in Milling Thin-Walled Parts, International Journal of Machine Tools and Manufacture, December 2018, Vol.135, pp 38-52. ISSN 0890-6955

[Zhang 2013] Zhang, X. and Ding, H. Note on a Novel Method for Machining Parameters Optimization in a Chatter-Free Milling Process, International Journal of Machine Tools and Manufacture, September 2013, Vol.72, pp 11-15. ISSN 0890-6955

[Bolsunovskiy 2013] Bolsunovskiy, S., et al. Thin-Walled Part Machining Process Parameters Optimization based on Finite-Element Modeling of Workpiece Vibrations, Procedia CIRP, 2013, Vol.8, pp 276-280. ISSN 2212-8271

[Dombovari 2010] Dombovari, Z., Altintas, Y., \& Stepan, G. The effect of serration on mechanics and stability of milling cutters. International Journal of Machine Tools and Manufacture, 50(6), 511-520. 